\title{
Restraint Stress during Pregnancy Rapidly Raises Kynurenic Acid Levels in Mouse Placenta and Fetal Brain
}

\author{
Francesca M. Notarangelo Robert Schwarcz
}

Maryland Psychiatric Research Center, Department of Psychiatry, University of Maryland School of Medicine, Baltimore, MD, USA

\section{Keywords}

Development · 3-Hydroxykynurenine $\cdot$ Kynurenine pathway . Quinolinic acid

\begin{abstract}
Stressful events during pregnancy adversely affect brain development and may increase the risk of psychiatric disorders later in life. Early changes in the kynurenine (KYN) pathway (KP) of tryptophan (TRP) degradation, which contains several neuroactive metabolites, including kynurenic acid (KYNA), 3-hydroxykynurenine (3-HK), and quinolinic acid (QUIN), may constitute a molecular link between prenatal stress and delayed pathological consequences. To begin testing this hypothesis experimentally, we examined the effects of a 2-h restraint stress on KP metabolism in pregnant FVB/N mice on gestational day 17. TRP, KYN, KYNA, 3-HK, and QUIN levels were measured in maternal and fetal plasma and brain, as well as in the placenta, immediately after stress termination and $2 \mathrm{~h}$ later. In the same animals, we determined the activity of TRP 2,3-dioxygenase (TDO) in the maternal liver and in the placenta. Compared to unstressed controls, mostly transient changes in KP metabolism were observed in all of the tissues examined. Specifically, stress caused significant elevations of KYNA levels in the maternal plasma,
\end{abstract}

\section{KARGER}

E-Mail karger@karger.com

www.karger.com/dne placenta, and fetal brain, and also resulted in increased levels of TRP and KYN in the placenta, fetal plasma, and fetal brain. In contrast, 3-HK and QUIN levels remained unchanged from control values in all tissues at any time point. In the maternal liver, TDO activity was increased $2 \mathrm{~h}$ after stress cessation. Taken together, these findings indicate that an acute stress during the late gestational period preferentially affects the KYNA branch of KP metabolism in the fetal brain. Possible long-term consequences for postnatal brain development and pathology remain to be examined.

(c) 2017 S. Karger AG, Basel

\section{Introduction}

Mounting evidence has established gestation as a period of vulnerability to environmental insults. Specifically, maternal exposure to stressful conditions adversely affects brain development in the fetus and can result in long-lasting changes in adulthood $[1,2]$. In humans, prenatal stress is considered a risk factor for the development of a series of behavioral alterations and has been associated with aggression, hyperactivity, anxiety, and cognitive problems later in life [3,4]. Moreover, exposure to adverse influences during the prenatal period has been

Francesca M. Notarangelo, $\mathrm{PhD}$

Maryland Psychiatric Research Center PO Box 21247

Baltimore, MD 21228 (USA)

E-Mail fnotarangelo@ mprc.umaryland.edu 
Fig. 1. The kynurenine pathway of TRP

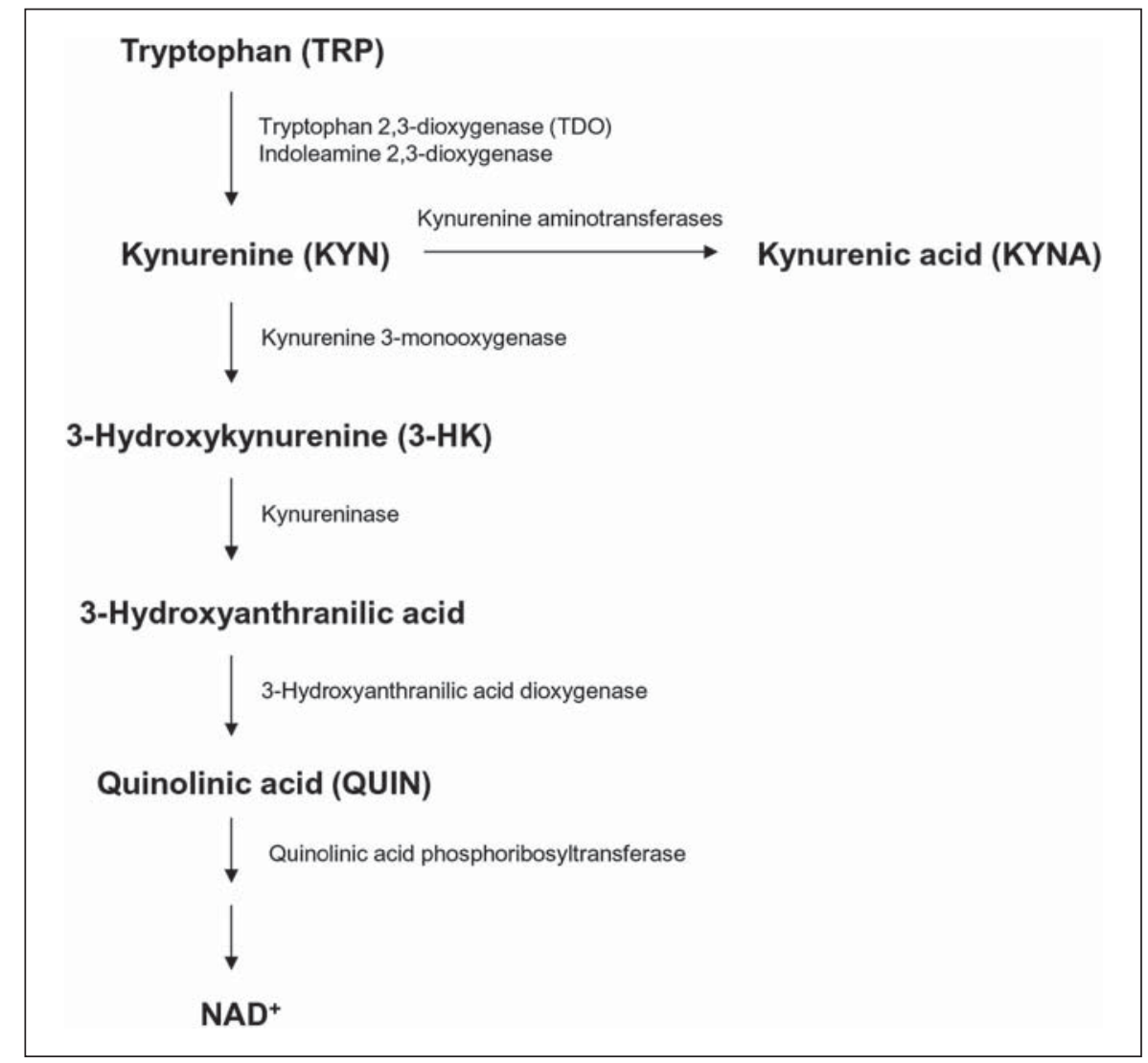
degradation.

linked to an increased risk of developing psychiatric disorders, including schizophrenia $[5,6]$. In rodents, prenatal stress has profound effects on the offspring, causing permanent neurobiological and behavioral alterations [7-9]. In particular, the progeny of stressed dams have an altered hypothalamic-pituitary-adrenal (HPA) axis and exhibit increased anxiety and impaired working memory [1]. Moreover, prenatal stress leads to long-lasting modifications in immune functions, exemplified by elevated cytokines in the brain and periphery, alteration in microglial morphology, and an enhanced immune response to inflammatory stimuli [10-12].

Stress is also known to cause changes in the kynurenine (KYN) pathway (KP) of tryptophan (TRP) degradation (Fig. 1). The KP contains several neuroactive metabolites, including kynurenic acid (KYNA), which can function as an antagonist of the $\alpha 7$ nicotinic acetylcholine $(\alpha 7 \mathrm{nACh})$ and the N-methyl-D-aspartate (NMDA) receptors and also affects other biologically relevant receptors $[13,14]$. In addition, the pathway contains, in a competing branch, the free radical generator 3-hydroxykynurenine (3-HK) and the NMDA receptor ago-

Increased Kynurenic Acid after Prenatal Stress nist quinolinic acid (QUIN) [15]. The link between stress and the KP is believed to be initiated by corticosterone (CORT), which directly activates TRP 2,3-dioxygenase (TDO), an enzyme that triggers the oxidative opening of TRP's indole ring and thus catalyzes the conversion of TRP to formylkynurenine (Fig. 1) [16]. This, in turn, results in increased levels of KYN and of downstream KP metabolites in both the brain and periphery [17-20]. Alone or together, these effects could play a role in a number of stress-related phenomena, ranging from normal physiological responses to acute and chronic pathological events $[21,22]$.

So far, the relationship between stress and KP metabolism has only been studied in adult animals. As maternal stress has adverse long-term consequences in the offspring and may play a role in the emergence of psychiatric diseases in adolescence and early adulthood, stress-induced prenatal KP impairments may also be functionally significant. Remarkably, in mammals, the brain levels of several key KP metabolites, including KYN, KYNA, 3-HK, and QUIN, are several-fold higher in the fetus than in the postnatal period, including adulthood [23], and di-

Dev Neurosci 2016;38:458-468 459 
rect manipulation of the KP during the last week of gestation results in several pathophysiologically interesting neurochemical and behavioral abnormalities as the offspring matures [24]. It follows that fluctuations of KP metabolites in the prenatal brain may be causally involved in the cascade linking stressful events during gestation to the emergence of a variety of clinically relevant abnormalities later in life [25-27]. In a first effort to directly investigate these putative relationships, the present study was designed to examine the effects of acute stress on KP metabolism in the fetus. To this end, we used mouse dams on gestational day (GD) 17, i.e., in the final stage of pregnancy.

\section{Materials and Methods}

\section{Chemicals}

L-TRP, 3-hydroxy-DL-kynurenine (3-HK), KYNA, $\left[{ }^{2} \mathrm{H}_{6}\right] \mathrm{L}-$ KYN, QUIN, pentafluoropropionic anhydride, 2,2,3,3,3-pentafluoro-1-propanol, and the TDO inhibitor 680C91 were obtained from Sigma-Aldrich (St. Louis, MO, USA). L-KYN sulfate (purity 99.4\%) was obtained from Sai Advantium (Hyderabad, India). $\left[{ }^{2} \mathrm{H}_{3}\right]$ QUIN was purchased from Synfine Research (Richmond Hill, ONT, Canada), and $\left[{ }^{2} \mathrm{H}_{5}\right] \mathrm{L}-\mathrm{TRP}$ was obtained from CDN Isotopes (Pointe-Claire, QUE, Canada). All other chemicals were obtained from various commercial suppliers and were of the highest available purity.

\section{Animals}

Male and female FVB/N mice (2-4 months; Jackson laboratory, Bar Harbor, ME, USA) were bred and housed in the animal facility of the University of Maryland School of Medicine. Detection of a copulation plug denoted GD1. Animals were maintained on a 12-h light/dark cycle in a temperature-controlled room with food and water ad libitum. To avoid litter effects, 2 embryos per litter were used in all studies, and the data were expressed as the average of litters. All studies were approved by the Institutional Animal Care and Use Committee of the University of Maryland School of Medicine.

\section{Restraint Stress}

Pregnant (GD17) mice ( $n=5-6$ per group) were placed in a well-ventilated cylindrical restrainer (Braintree Scientific, Braintree, MA, USA) for $2 \mathrm{~h}$ (stress group) or left undisturbed (control group). The animals were then euthanized immediately (" $0 \mathrm{~h}$ ”) or $2 \mathrm{~h}$ after the cessation of stress. Maternal brain, liver, and blood ("plasma"; collected in EDTA-containing vials to avoid clotting), as well as placenta, fetal brain, and fetal plasma, were rapidly collected on ice and stored at $-80^{\circ} \mathrm{C}$ until analysis.

\section{CORT Determination}

Levels of CORT were determined by radioimmunoassay in 10 $\mu \mathrm{L}$ of thawed plasma according to protocols provided by the commercial manufacturer (MP Biochemicals, Orangeburg, NY, USA).
TDO Assay

Maternal liver and placenta were thawed out and homogenized $(1: 10, \mathrm{w} / \mathrm{v})$ in $100 \mathrm{mM}$ HEPES buffer $(\mathrm{pH} 7.4)$, and liver homogenate was diluted further $(1: 10, v / v)$ in the same buffer. Fifty microliters of the tissue homogenates were incubated at $37^{\circ} \mathrm{C}(2 \mathrm{~h}$ for liver, $4 \mathrm{~h}$ for placenta) in a solution containing $10 \mu \mathrm{M}$ hematin, 25 $\mu \mathrm{M}$ ascorbic acid, and $200 \mu \mathrm{M}$ TRP in a total volume of $100 \mu \mathrm{L}$. Blanks were obtained by adding the specific TDO inhibitor 680C91 ( $50 \mu \mathrm{M}$ final concentration) to the incubation solution. The reaction was stopped by the addition of $25 \mu \mathrm{L}$ of $6 \%$ perchloric acid, and the samples were then incubated for $20 \mathrm{~min}$ at $60^{\circ} \mathrm{C}$. After centrifugation $(16,000 \mathrm{~g}, 10 \mathrm{~min}), 20 \mu \mathrm{L}$ of the supernatant were applied to high-performance liquid chromatography (HPLC), and KYN was detected fluorometrically (see below).

\section{Measurement of TRP and KYN by HPLC}

For the determination of TRP and KYN in maternal and fetal plasma, the samples were thawed and diluted in ultrapure water $(1: 1,000, \mathrm{v} / \mathrm{v}$ for TRP; $1: 2, \mathrm{v} / \mathrm{v}$ for KYN), and $25 \mu \mathrm{L}$ of $6 \%$ perchloric acid were added to $100 \mu \mathrm{L}$ of the preparations. Precipitated proteins were removed by centrifugation $(16,000 \mathrm{~g}, 10 \mathrm{~min})$, and $20 \mu \mathrm{L}$ of the resulting supernatant were applied to a $3-\mu \mathrm{m} \mathrm{C} 18$ reverse phase HPLC column $(80 \times 4.6 \mathrm{~mm}$; ESA, Chelmsford, MA, USA), using a mobile phase containing $250 \mathrm{mM}$ zinc acetate, $50 \mathrm{mM}$ sodium acetate, and 5\% (for TRP) or 3\% (for KYN) acetonitrile ( $\mathrm{pH}$ adjusted to 6.2 with glacial acetic acid). Eluted at a flow rate of $1.0 \mathrm{~mL} / \mathrm{min}$, the metabolites were detected fluorometrically (TRP, excitation: $285 \mathrm{~nm}$, emission: $365 \mathrm{~nm}$; KYN, excitation: $365 \mathrm{~nm}$, emission: $480 \mathrm{~nm}$; 200a fluorescence detector; PerkinElmer, Waltham, MA, USA).

\section{Measurement of TRP, KYN, and QUIN by GC/MS}

To measure TRP, KYN, and QUIN levels in tissue, the stored samples were thawed and sonicated $(1: 5, \mathrm{w} / \mathrm{v}$ for maternal brain; $1: 10, \mathrm{w} / \mathrm{v}$ for fetal brain and placenta) in ultrapure water. The homogenates were further diluted in $0.1 \%$ ascorbic acid (final dilutions: 1:20 for maternal brain, 1:50 for fetal brain, and 1:100 for placenta). For the determination of QUIN in plasma, thawed maternal and fetal samples were diluted in $0.1 \%$ ascorbic acid $(1: 10, \mathrm{v} / \mathrm{v})$.

Fifty microliters of an internal standard mix $\left(\left[{ }^{2} \mathrm{H}_{3}\right]\right.$ QUIN, $\left[{ }^{2} \mathrm{H}_{6}\right] \mathrm{L}-\mathrm{KYN}$, and $\left.\left[{ }^{2} \mathrm{H}_{5}\right] \mathrm{L}-\mathrm{TRP}\right)$ were added to $50 \mu \mathrm{L}$ of each sample, and proteins were precipitated with $50 \mu \mathrm{L}$ of acetone. After centrifugation $(13,700 \mathrm{~g}, 5 \mathrm{~min}), 50 \mu \mathrm{L}$ of methanol:chloroform (20:50) were added to the supernatant, and the samples were centrifuged again $(13,700 \mathrm{~g}, 10 \mathrm{~min})$. The upper layer was added to a glass tube and dried for $90 \mathrm{~min}$. The samples were then derivatized with $120 \mu \mathrm{L}$ of 2,2,3,3,3-pentafluoro-1-propanol and $130 \mu \mathrm{L}$ of pentafluoropropionic anhydride at $75^{\circ} \mathrm{C}$ for $30 \mathrm{~min}$, dried and reconstituted in $50 \mu \mathrm{L}$ of ethyl acetate; $1 \mu \mathrm{L}$ was then used for analysis by gas chromatography/mass spectrometry [76].

\section{Measurement of 3-HK and KYNA}

For measurement of 3-HK and KYNA, thawed fetal plasma (1:4, v/v for 3-HK, 1:50, v/v for KYNA) and fetal brain homogenate (1:20 final for 3-HK, and 1:50 final for KYNA) were diluted in ultrapure water. Placental homogenate (final dilutions 1:20 for 3-HK, and 1:100 for KYNA) and maternal plasma (1:2, v/v for $3-\mathrm{HK}$, and 1:10, v/v for KYNA) were diluted in ultrapure water. A dilution of 1:5 $(\mathrm{w} / \mathrm{v})$ was used for the determination of both KYNA and 3-HK in maternal brain homogenate. 


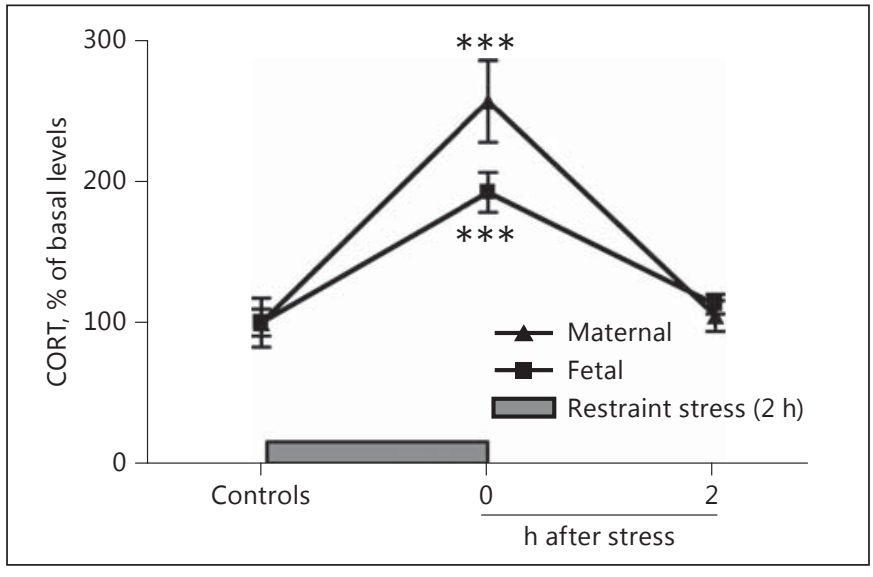

Fig. 2. Stress-induced elevation of CORT levels in maternal and fetal plasma. CORT was determined in control mice or immediately and $2 \mathrm{~h}$ after the cessation of stress. Data are the mean \pm SEM ( $n=5-6$ per group) and are expressed as a percentage of endogenous values. ${ }^{* * *} p<0.001$ versus controls (1-way ANOVA, followed by Bonferroni post hoc test).

Twenty-five microliters of $6 \%$ perchloric acid were added to 100 $\mu \mathrm{L}$ of the samples, and precipitated proteins were removed by centrifugation $(16,000 \mathrm{~g}, 10 \mathrm{~min})$. For KYNA determination, $20 \mu \mathrm{L}$ of the resulting supernatant were injected to a $3-\mu \mathrm{m} C 18$ reverse phase HPLC column (HR-80, $80 \times 4.6 \mathrm{~mm}$; ESA), using a mobile phase containing $250 \mathrm{mM}$ zinc acetate, $50 \mathrm{~mm}$ sodium acetate, and $3 \%$ acetonitrile ( $\mathrm{pH}$ adjusted to 6.2 with glacial acetic acid) at a flow rate of $1.0 \mathrm{~mL} / \mathrm{min}$. In the eluate, KYNA was detected fluorometrically (excitation: $344 \mathrm{~nm}$, emission: $398 \mathrm{~nm}$; S200a fluorescence detector; Perkin Elmer). For 3-HK determination, $20 \mu \mathrm{L}$ of the supernatant were applied to a $3-\mu \mathrm{m}$ HPLC column $(80 \times 4.6 \mathrm{~mm}$; ESA $)$, using a mobile phase consisting of $1.5 \%$ acetonitrile, $0.9 \%$ triethylamine, $0.59 \%$ phosphoric acid, $0.27 \mathrm{mM}$ EDTA, and $8.9 \mathrm{~mm}$ sodium heptane sulfonic acid, and a flow rate of $0.5 \mathrm{~mL} / \mathrm{min}$. In the eluate, $3-\mathrm{HK}$ was detected electrochemically using a HTEC 500 detector (oxidation potential $+0.5 \mathrm{~V}$; Eicom Corp., San Diego, CA, USA).

Statistical Analysis

Results are expressed as the mean \pm SEM. One-way and 2-way ANOVA followed by the Bonferroni post hoc test or Student $t$ test were used to determine statistical significance. To measure the relationship between metabolites in different tissues, Pearson correlation analysis was performed. A $p$ value $<0.05$ was considered significant.

\section{Results}

\section{Effect of Acute Stress on Plasma CORT and TDO} Activity

To evaluate the response of pregnant mice to acute restraint stress, we measured CORT in maternal and fetal plasma. Compared to basal values, CORT levels were sig-

Increased Kynurenic Acid after Prenatal

Stress nificantly elevated $(p<0.001)$ in both samples immediately after the termination of stress and returned to basal levels after an additional $2 \mathrm{~h}$ (Fig. 2). The increase in CORT was slightly higher in maternal than in fetal plasma (256 and 192\%, respectively; $p<0.05,2$-way ANOVA followed by Bonferroni post hoc test). Interestingly, CORT levels in maternal plasma correlated positively with CORT levels in fetal plasma $(p<0.0001)$.

TDO activity in the maternal liver trended to be elevated immediately after the termination of stress, and the increase reached statistical significance $2 \mathrm{~h}$ later $(p<0.05$; Fig. 3a). We also observed a trend toward increased TDO activity in the placenta immediately after the termination of stress ( $p=0.07,1$-way ANOVA, followed by Bonferroni post hoc test; Fig. 3b). However, TDO activity was undetectable in the fetal liver of both the control and stressed mice (data not shown).

\section{TRP and KP Metabolites in Maternal Brain and \\ Plasma}

To examine the effect of acute stress on the dynamics of the maternal KP metabolism, we determined TRP, KYN, KYNA, 3-HK, and QUIN levels in the brain and plasma of control and stressed dams immediately and $2 \mathrm{~h}$ after the termination of stress. With one exception (an increase in KYNA levels in the maternal plasma immediately after the termination of stress; $p<0.05)$, acute stress had no significant effect on TRP or any of the KP metabolites in either the maternal brain (Table 1) or the maternal plasma ( $p>0.05$ in both cases; 1-way ANOVA, followed by Bonferroni post hoc test; Table 2).

\section{TRP and KP Metabolites in the Placenta and Fetal Plasma}

Despite a tendency toward higher TDO activity (see above), TRP levels in the placenta were transiently elevated immediately after stress ( $p<0.05$; Fig. 4$)$. KYN and KYNA levels were also increased immediately after the cessation of stress ( $p<0.05$ and $p<0.01$, respectively), but returned to control levels after $2 \mathrm{~h}$. In contrast, stress did not affect either 3-HK or QUIN levels in the placenta (Fig. 4).

Analyzed by $t$ test, fetal plasma contained higher basal levels of KYN $(p<0.001)$, KYNA $(p<0.05)$, and QUIN $(p<0.001)$ than maternal plasma (Fig. 5; Table 2). Acute restraint stress caused significant elevations in TRP and KYN levels in fetal plasma ( $p<0.01$ each; Fig. 5$)$ immediately after the termination of stress, and KYN levels remained elevated $2 \mathrm{~h}$ after stress $(p<0.05)$. However, we did not detect significant stress-induced changes in KYNA, 3-HK or QUIN levels in these samples (Fig. 5).

Dev Neurosci 2016;38:458-468 461 
Fig. 3. Effect of stress on TDO activity in the maternal liver (a) and placenta (b). Enzyme activity was measured in control mice or immediately and $2 \mathrm{~h}$ after the cessation of stress. Data are the mean \pm SEM ( $n=5-6$ per group). ${ }^{* *} p<0.01$ versus controls (1-way ANOVA, followed by Bonferroni post hoc test).

Table 1. Effect of restraint stress on TRP and KP metabolites in the maternal brain
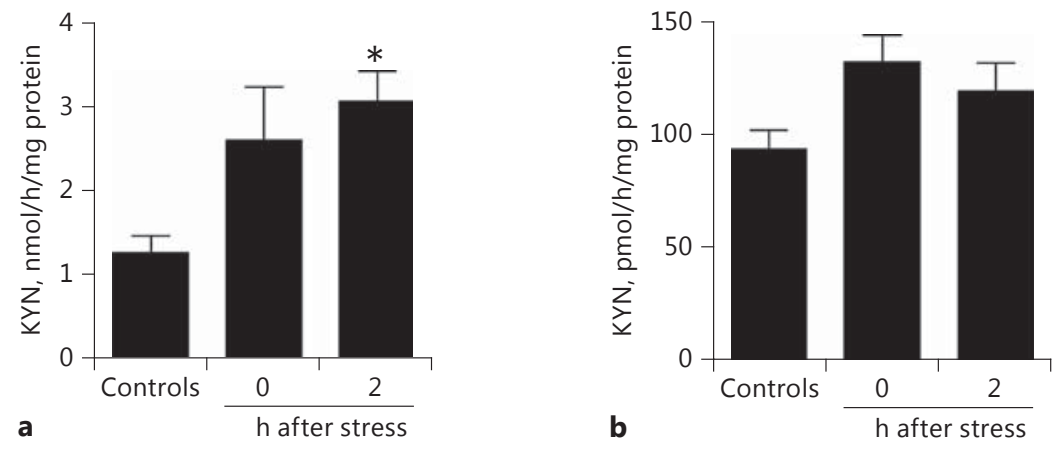

\begin{tabular}{lccc}
\hline & Controls & 0 h after stress & 2 h after stress \\
\hline TRP, pmol/mg protein & $308.1 \pm 9.8$ & $367.7 \pm 25.8$ & $302.3 \pm 3.0$ \\
KYN, pmol/mg protein & $12.6 \pm 0.5$ & $14.1 \pm 2.0$ & $14.2 \pm 1.2$ \\
KYNA, fmol/mg protein & $28.5 \pm 2.0$ & $36.7 \pm 4.5$ & $35.9 \pm 2.8$ \\
3-HK, fmol/mg protein & $862.6 \pm 89.0$ & $815.6 \pm 157.7$ & $1,041.9 \pm 58.5$ \\
QUIN, fmol/mg protein & $473.0 \pm 25.4$ & $472.4 \pm 55.0$ & $500.0 \pm 37.7$ \\
\hline
\end{tabular}

Data are the mean \pm SEM ( $n=5-6$ per group).

\section{TRP and KP Metabolites in the Fetal Brain}

The tissue concentrations of all metabolites analyzed were substantially higher (all $p<0.001, t$ test) in the fetal brain than in the maternal brain. Specifically, TRP and KYN levels were approximately 3 and 7 times higher, respectively, KYNA levels were approximately 20-fold higher, and 3-HK and QUIN levels were both approximately 4-5 times higher in fetal compared to maternal brain (Fig. 6; Table 1).

Similar to the results obtained in the placenta and fetal plasma, acute stress caused significant increases in TRP $(p<0.001)$, KYN $(p<0.01)$, and KYNA $(p<0.01)$ levels in the fetal brain immediately after stress. Two hours later, KYN levels remained elevated, whereas TRP and KYNA levels had returned to control values (Fig. 6). No stress-related changes in 3-HK or QUIN content were detected in the fetal brain (Fig. 6).

Interestingly, TRP levels in the fetal brain correlated with TRP levels in fetal plasma $(p<0.001)$ and placenta $(p<0.0001)$, and KYNA levels in the fetal brain correlated positively with TRP levels in placenta $(p<0.01)$, fetal plasma $(p=0.056)$, and fetal brain $(p<0.001)$, as well as with KYNA levels in fetal plasma $(p<0.01)$.
Table 2. Effect of restraint stress on TRP and KP metabolites in maternal plasma

\begin{tabular}{lccc}
\hline & Controls & 0 h after stress & 2 h after stress \\
\hline TRP, pmol $/ \mu \mathrm{L}$ & $58.6 \pm 4.6$ & $70.2 \pm 5.7$ & $68.9 \pm 6.5$ \\
$\mathrm{KYN}, \mathrm{pmol} / \mu \mathrm{L}$ & $3.7 \pm 0.5$ & $3.3 \pm 0.3$ & $3.5 \pm 0.2$ \\
$\mathrm{KYNA}, \mathrm{fmol} / \mu \mathrm{L}$ & $62.4 \pm 6.6$ & $116.3 \pm 19.4^{*}$ & $103.1 \pm 12.5$ \\
$3-\mathrm{HK}, \mathrm{fmol} / \mu \mathrm{L}$ & $27.3 \pm 6.1$ & $17.2 \pm 2.8$ & $35.3 \pm 7.1$ \\
$\mathrm{QUIN}, \mathrm{fmol} / \mu \mathrm{L}$ & $176.2 \pm 13.4$ & $215.0 \pm 15.2$ & $171.7 \pm 10.9$ \\
\hline
\end{tabular}

Data are the mean \pm SEM $(n=5-6$ per group). $* p<0.05$ vs. controls (1-way ANOVA, followed by Bonferroni post hoc test).

\section{Discussion}

The present study, which was designed to examine the short-term effects of an acute physical stress on KP metabolism at a late gestational stage, revealed several interesting phenomena. First, most of the changes seen following the 2-h restraint were transient, i.e., they were more pronounced immediately after cessation of the restraint than $2 \mathrm{~h}$ later. Second, with the exception of an increase 


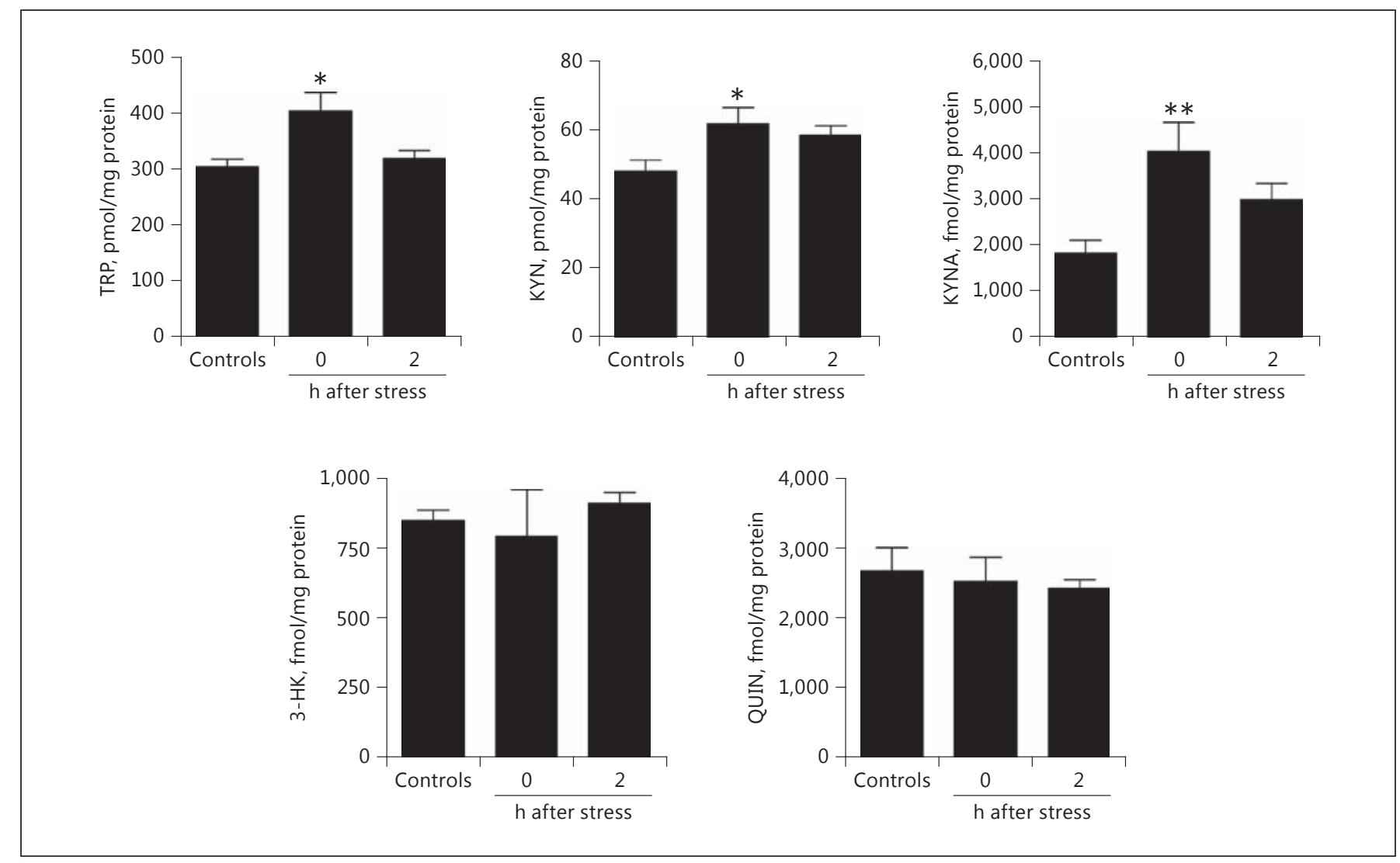

Fig. 4. Effect of stress on TRP, KYN, and KYNA in the placenta. TRP and KP metabolites were measured in control mice or immediately and $2 \mathrm{~h}$ after the cessation of stress. Data are the mean \pm SEM ( $n=5-6$ per group). ${ }^{*} p<0.05,{ }^{* *} p<0.01$ versus controls (1-way ANOVA, followed by Bonferroni post hoc test).

in plasma KYNA levels, stress did not cause significant changes in KP metabolite levels in maternal blood or brain. Third, stress-induced KP changes in the placenta may have affected fetal KP metabolism. Finally, the relatively brief episode of restraint did not influence either 3-HK or QUIN levels in any of the tissues studied, indicating an unexpected, selective effect of stress on the KYNA branch of the metabolic cascade.

As confirmed here, acute stress raises circulating levels of CORT not only in maternal but also in fetal plasma [28, 29]. In line with the fact that TDO activity is readily stimulated by CORT, and therefore upregulated in adult animals under stressful conditions [18, 20, 30, 31], we also observed a stress-induced increase in TDO activity in the maternal liver. Although not reaching statistical significance, a similar response to stress was observed in the placenta, which was found to contain comparatively low but clearly detectable TDO activity - in agreement with reports of placental TDO expression $[32,33]$. In accor-

Increased Kynurenic Acid after Prenatal Stress dance with a previous study reporting the absence of TDO activity in the liver of young rats [34], we were not able to measure TDO activity in fetal liver tissue homogenate in either basal conditions or after stress. Of note in this context, the fetal liver is not fully functional during the prenatal period, as maturation is gradual and continues after birth [35].

In spite of the trend toward higher TDO activity, the stress-induced increase in placental and fetal TRP levels seen in the present study was not unexpected since rapid TRP elevations in response to immobilization have been previously observed in both the plasma and brain of adult male rats [36, 37]. TRP levels are also raised in the fetal brain when pregnant rats are stressed by crowding during the final week of gestation [38], though, to our knowledge, this effect has so far not been authenticated in mice. Although the underlying mechanism(s) may also include compensatory downregulation of other TRP-degrading placental enzymes during the prenatal period [39] and/or

Dev Neurosci 2016;38:458-468 DOI: $10.1159 / 000455228$ 


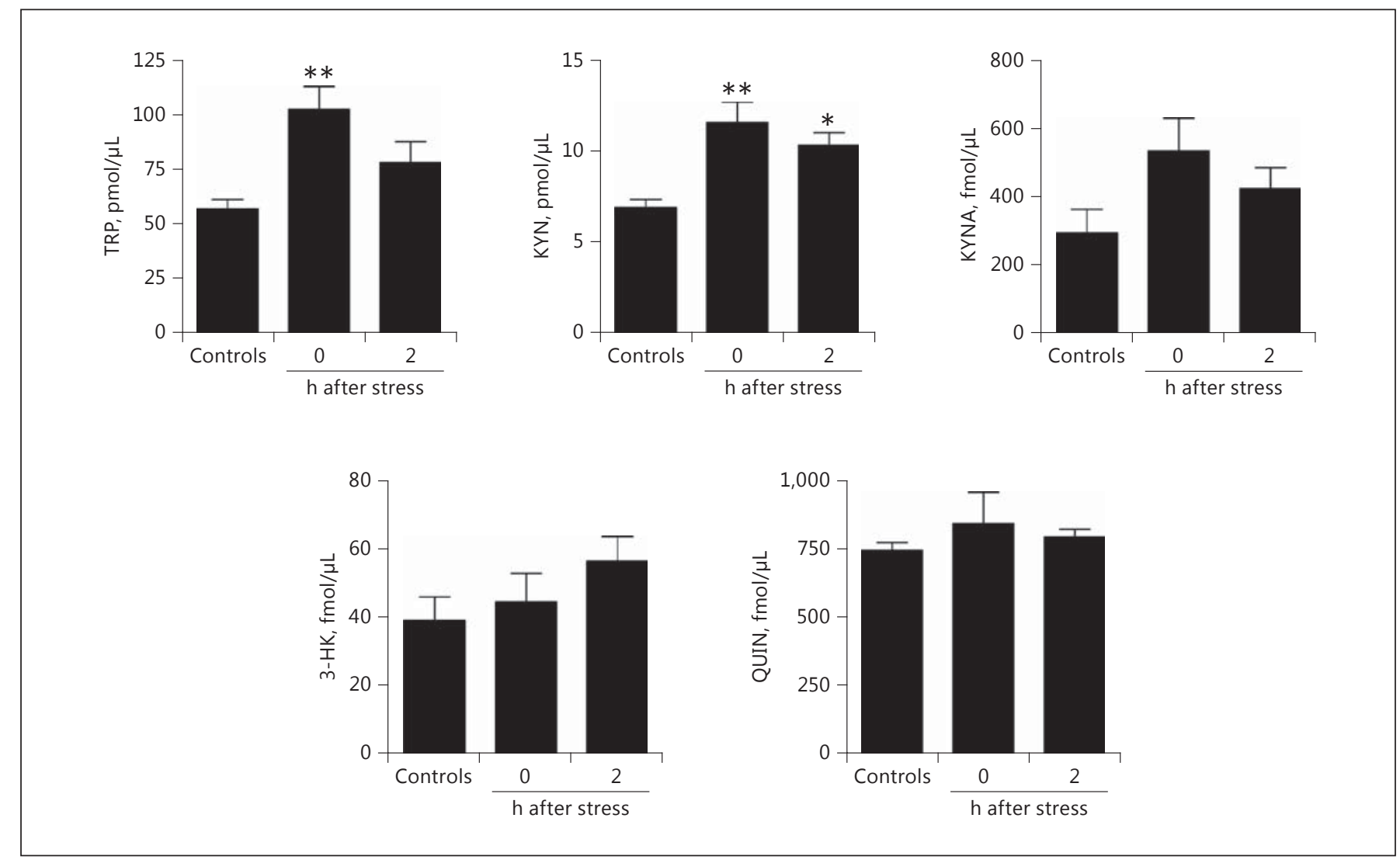

Fig. 5. Stress-induced increases in the levels of TRP and KYN in the fetal plasma. TRP and KP metabolites were measured in control mice or immediately and $2 \mathrm{~h}$ after the cessation of stress. Data are the mean \pm SEM $(n=5-6$ per group). ${ }^{*} p<0.05,{ }^{* *} p<0.01$ versus controls (1-way ANOVA, followed by Bonferroni post hoc test).

direct effects of steroid hormones on TRP metabolism [40-42], the elevated TRP levels seen in the highly vascularized placenta [43] immediately after restraint of the dam were more likely related to increased free TRP or to the presence of maternal blood where we observed a trend toward increased TRP levels (Table 2).

The qualitative and quantitative similarity between stress-related changes in the levels of TRP, KYN, and KYNA in the placenta and the fetal brain shown here suggests a close functional relationship between the two tissues. The relevance of the placenta for healthy fetal development is indeed well established [44], and its pathophysiologically significant role during maternal insults has been documented [45-47]. More specifically, the placenta is known to regulate the transport of amino acids [48] and the synthesis of several neuroactive factors that can influence fetal brain development, including the TRP metabolite serotonin [49]. KP metabolites and enzymes may also play a role in the placenta both under physiological conditions and when the organ is compromised [32, 5053]. Notably, as both TRP and KYN pass easily from the placenta to the fetus $[42,51,54,55]$, the transient increases in the fetal levels of these two compounds seen here in response to maternal stress may be at least in part caused by direct transfer from the placenta. KYNA, in contrast, does not penetrate readily from the placenta into the fetus [55], i.e., the stress-induced KYNA elevation in the embryonic brain likely reflected local synthesis in the fetal tissue itself due to higher substrate availability, as kynurenine aminotransferase activity in the placenta or fetal brain is not affected by stress (data not shown). KYN is indeed enzymatically transaminated to KYNA in the fetal brain [56], and we recently demonstrated the efficient synthesis of KYNA from KYN, as well as the prompt liberation of newly produced KYNA, using fetal brain tissue slices [57]. Interestingly, however, 3-HK production from $\mathrm{KYN}$ was essentially undetectable in these and other in vitro experiments [Notarangelo et al., in preparation]. 


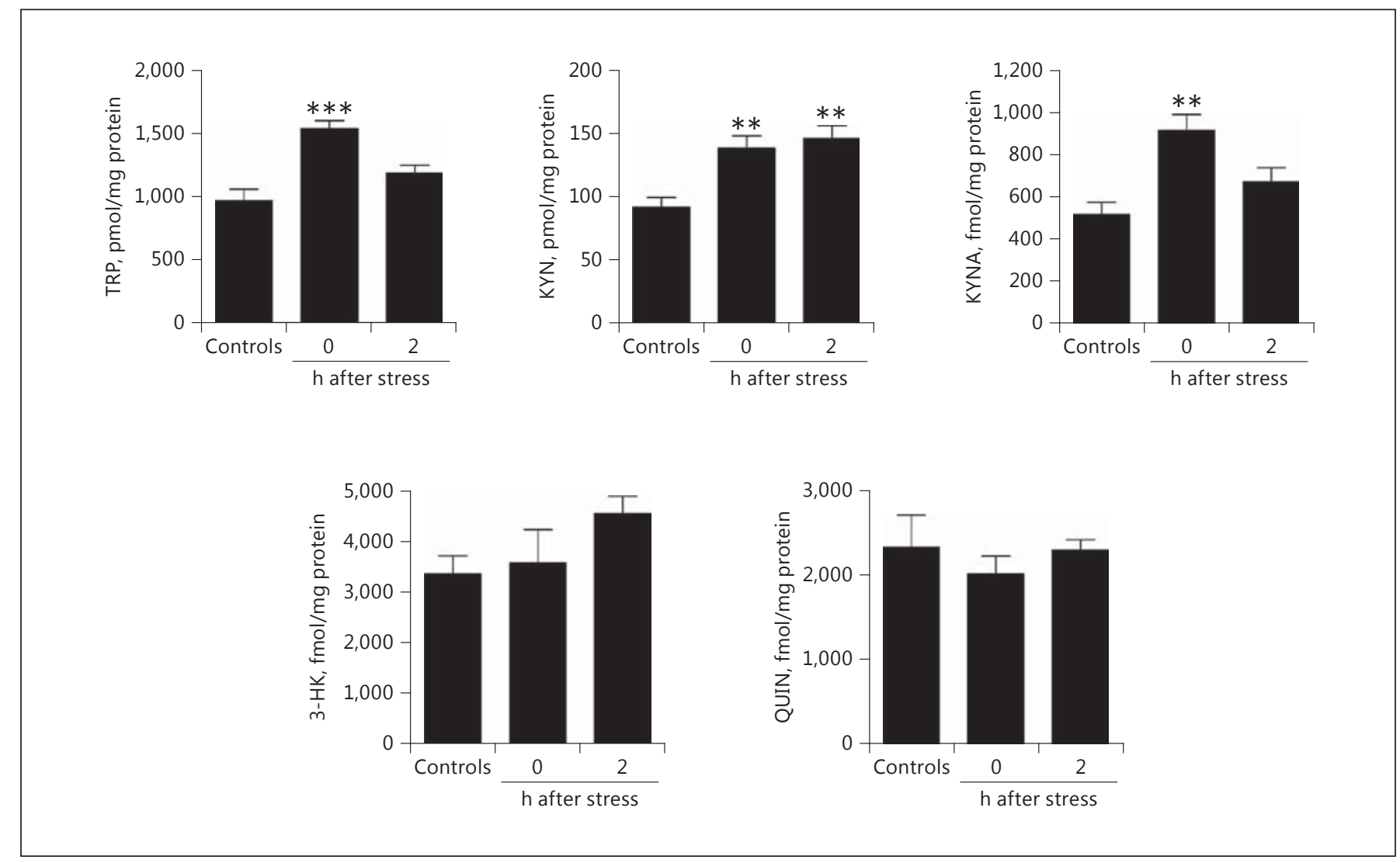

Fig. 6. Stress-induced increases in the levels of TRP, KYN and KYNA in the fetal brain. TRP and KP metabolites were measured in control mice or immediately and $2 \mathrm{~h}$ after the cessation of stress. Data are the mean \pm SEM ( $n=5-6$ per group). ${ }^{* *} p<0.01,{ }^{* * *} p<0.001$ versus controls (1-way ANOVA, followed by Bonferroni post hoc test).

Therefore, while the source of 3-HK and QUIN in the fetal brain remains to be elaborated, the present results are consistent with a scenario in which the placenta, by efficiently providing TRP and KYN to the fetus, critically mediates the effects of maternal stress on the embryo.

Stress during pregnancy not only affects the fetal brain acutely but also increases the risk to the offspring of developing major psychiatric disorders, including depression and schizophrenia $[25,58]$. Elevated fetal brain levels of KYNA, an established neuromodulator in the adult mammalian brain [24], may be one of the factors that contribute to these impairments and dysfunctions later in life. Thus, KYNA is an endogenous antagonist of $\alpha 7 \mathrm{nACh}$ and NMDA receptors, both of which play critical roles in brain development $[59,60]$, and can also target 2 other receptors, the aryl hydrocarbon receptor and the $G$ protein-coupled receptor GPR35, which have not yet been evaluated as participants in early life events $[13,14]$.
Alone or together, these effector sites may react unconventionally to a sudden KYNA surge in the prenatal period and cause abnormal effects downstream. Of potential relevance in this context is the fact that basal brain concentrations of several KP metabolites, including KYNA, are substantially higher prenatally than postnatally [23]. Cause(s) and physiological ramifications of these elevated metabolite levels, as well as possible implications for pathological events during the perinatal period [61], await further clarification.

In rodents, pharmacological interventions that produce increases in brain KYNA levels during the last week of gestation result in chemical, structural, electrophysiological, and cognitive impairments in adulthood [62-67]. Initial support for causality has recently been obtained by the observation that these cognitive impairments can be prevented by the perinatal administration of the $\alpha 7 \mathrm{nACh}$ receptor agonist choline [23]. Notably, prenatal stress 
causes $a 7 \mathrm{nACh}$ receptor abnormalities in the offspring $[68,69]$, and prenatal dietary choline supplementation has been shown to have positive behavioral effects in a variety of informative animal models [70-72]. It is therefore tempting to speculate that the acute effect of prenatal stress on KYNA described here, especially if accompanied and potentially exacerbated by KP abnormalities caused by infections or other immune activations during pregnancy $[32,53,73-75]$, may be directly related to behavioral impairments later in life and the etiology of major brain diseases.

In conclusion, the present study demonstrated a significant, transient increase of KYNA levels in the fetal brain after acute stress, raising the prospect that KYNA plays a causative role in the development of postnatal abnormalities and, possibly, of psychiatric disorders in humans. Ongoing studies in our laboratory are designed to evaluate the consequences of repeated or chronic stress and infections during pregnancy on fetal KP metabolism, to examine possible sex-specific, long-term effects in adolescence and adulthood, and to predictably exacerbate or ameliorate long-term impairments by targeted interventions at various stages in life.

\section{Acknowledgements}

This study was supported in part by NIH grant P50 MH103222. The authors thank Kevin Wons and Nicholas Todd for technical support and contribution to the study.

\section{Disclosure Statement}

The authors have no conflicts of interest to disclose.

\section{References}

1 Maccari S, Darnaudery M, Morley-Fletcher S, Zuena AR, Cinque C, Van Reeth O: Prenatal stress and long-term consequences: implications of glucocorticoid hormones. Neurosci Biobehav Rev 2003;27:119-127.

2 Glover V, O'Connor TG, O’Donnell K: Prenatal stress and the programming of the HPA axis. Neurosci Biobehav Rev 2010;35:17-22.

3 Li J, Olsen J, Vestergaard M, Obel C: Attention-deficit/hyperactivity disorder in the offspring following prenatal maternal bereavement: a nationwide follow-up study in Denmark. Eur Child Adolesc Psychiatry 2010;19: 747-753.

4 Talge NM, Neal C, Glover V, Early Stress TR, Prevention Science Network F, Neonatal Experience on C, Adolescent Mental H: Antenatal maternal stress and long-term effects on child neurodevelopment: how and why? J Child Psychol Psychiatry 2007;48:245-261.

5 Brown AS: The environment and susceptibility to schizophrenia. Prog Neurobiol 2011;93: $23-58$.

6 Khashan AS, Abel KM, McNamee R, Pedersen MG, Webb RT, Baker PN, Kenny LC, Mortensen PB: Higher risk of offspring schizophrenia following antenatal maternal exposure to severe adverse life events. Arch Gen Psychiatry 2008;65:146-152.

7 Maccari S, Darnaudery M, van Reeth O: Hormonal and behavioural abnormalities induced by stress in utero: an animal model for depression. Stress 2001;4:169-181.

8 Dong E, Dzitoyeva SG, Matrisciano F, Tueting P, Grayson DR, Guidotti A: Brain-derived neurotrophic factor epigenetic modifications associated with schizophrenia-like phenotype induced by prenatal stress in mice. Biol Psychiatry 2015;77:589-596.
9 Wei L, Hao J, Lacher RK, Abbott T, Chung L, Colangelo CM, Kaffman A: Early-life stress perturbs key cellular programs in the developing mouse hippocampus. Dev Neurosci 2015;37:476-488.

10 Diz-Chaves Y, Astiz M, Bellini MJ, Garcia-Segura LM: Prenatal stress increases the expression of proinflammatory cytokines and exacerbates the inflammatory response to LPS in the hippocampal formation of adult male mice. Brain Behav Immun 2013;28:196-206.

11 Diz-Chaves Y, Pernia O, Carrero P, GarciaSegura LM: Prenatal stress causes alterations in the morphology of microglia and the in flammatory response of the hippocampus of adult female mice. J Neuroinflammation 2012;9:71.

12 Vanbesien-Mailliot CC, Wolowczuk I, Mairesse J, Viltart O, Delacre M, Khalife J, Chartier-Harlin MC, Maccari S: Prenatal stress has pro-inflammatory consequences on the immune system in adult rats. Psychoneuroendocrinology 2007;32:114-124.

13 Moroni F, Cozzi A, Sili M, Mannaioni G: Kynurenic acid: a metabolite with multiple actions and multiple targets in brain and periphery. J Neural Transm (Vienna) 2012;119: 133-139.

14 Stone TW, Stoy N, Darlington LG: An expanding range of targets for kynurenine metabolites of tryptophan. Trends Pharmacol Sci 2013;34:136-143.

15 Schwarcz R, Bruno JP, Muchowski PJ, Wu HQ: Kynurenines in the mammalian brain: when physiology meets pathology. Nat Rev Neurosci 2012;13:465-477.
16 Hayaishi O, Rothberg S, Mehler AH, Saito Y: Studies on oxygenases; enzymatic formation of kynurenine from tryptophan. J Biol Chem 1957;229:889-896.

17 Pawlak D, Takada Y, Urano T, Takada A: Serotonergic and kynurenic pathways in rats exposed to foot shock. Brain Res Bull 2000;52: 197-205.

18 Gibney SM, Fagan EM, Waldron AM, O’Byrne J, Connor TJ, Harkin A: Inhibition of stress-induced hepatic tryptophan 2,3-dioxygenase exhibits antidepressant activity in an animal model of depressive behaviour. Int J Neuropsychopharmacol 2014;17:917-928.

19 Miura H, Ozaki N, Shirokawa T, Isobe K Changes in brain tryptophan metabolism elicited by ageing, social environment, and psychological stress in mice. Stress $2008 ; 11$ : 160-169.

20 Curzon G, Green AR: Effects of immobilization on rat liver tryptophan pyrrolase and brain 5-hydroxytryptamine metabolism. Br J Pharmacol 1969;37:689-697.

21 Lupien SJ, McEwen BS, Gunnar MR, Heim C: Effects of stress throughout the lifespan on the brain, behaviour and cognition. Nat Rev Neurosci 2009;10:434-445.

22 McEwen BS, Bowles NP, Gray JD, Hill MN, Hunter RG, Karatsoreos IN, Nasca C: Mechanisms of stress in the brain. Nat Neurosci 2015;18:1353-1363.

23 Notarangelo FM, Pocivavsek A: Elevated kynurenine pathway metabolism during neurodevelopment: implications for brain and behavior. Neuropharmacology 2017;112:275285. 
24 Pocivavsek A, Notarangelo FM, Wu HQ, Bruno JP, Schwarcz R: Astrocytes as pharmacological targets in the treatment of schizophrenia: focus on kynurenic acid; in Pletnikov $\mathrm{M}$, Waddington J (eds): Modeling the Psychopathological Dimensions of Schizophrenia. San Diego, Elsevier, 2015, pp 423-443.

25 Babenko O, Kovalchuk I, Metz GA: Stress-induced perinatal and transgenerational epigenetic programming of brain development and mental health. Neurosci Biobehav Rev 2015;48:70-91.

26 Bock J, Wainstock T, Braun K, Segal M: Stress in utero: prenatal programming of brain plasticity and cognition. Biol Psychiatry 2015;78: 315-326.

27 Nilsen RM, Bjorke-Monsen AL, Midttun O, Nygard O, Pedersen ER, Ulvik A, Magnus P, Gjessing HK, Vollset SE, Ueland PM: Maternal tryptophan and kynurenine pathway metabolites and risk of preeclampsia. Obstet Gynecol 2012;119:1243-1250.

28 Erisman S, Carnes M, Takahashi LK, Lent SJ: The effects of stress on plasma ACTH and corticosterone in young and aging pregnant rats and their fetuses. Life Sci 1990;47:15271533.

29 Bingham BC, Sheela Rani CS, Frazer A, Strong R, Morilak DA: Exogenous prenatal corticosterone exposure mimics the effects of prenatal stress on adult brain stress response systems and fear extinction behavior. Psychoneuroendocrinology 2013;38:2746-2757.

30 Nemeth S, Vigas M: Adrenal hormones and increase of liver tyrosine aminotransferase and tryptophan pyrrolase activity after immobilization in rats. Endocrinol Exp 1975;9:100104.

31 Green AR, Curzon G: Effects of hydrocortisone and immobilization on tryptophan metabolism in brain and liver of rats of different ages. Biochem Pharmacol 1975;24:713-716.

32 Manuelpillai U, Ligam P, Smythe G, Wallace EM, Hirst J, Walker DW: Identification of kynurenine pathway enzyme mRNAs and metabolites in human placenta: up-regulation by inflammatory stimuli and with clinical infection. Am J Obstet Gynecol 2005; 192:280288.

33 Suzuki S, Tone S, Takikawa O, Kubo T, Kohno I, Minatogawa Y: Expression of indoleamine 2,3-dioxygenase and tryptophan 2,3-dioxygenase in early concepti. Biochem J 2001;355:425-429.

34 Roper MD, Franz JM: Glucocorticoid control of the development of tryptophan oxygenase in the young rat. J Biol Chem 1977;252:43544360.

35 Zorn AM: Liver development. StemBook DOI: 10.3824/stembook.1.25.1.

36 Curzon G, Joseph MH, Knott PJ: Effects of immobilization and food deprivation on rat brain tryptophan metabolism. J Neurochem 1972;19:1967-1974.
37 Nemeth S: The effect of stress on the activity of hepatic tryptophan pyrrolase, of tyrosine aminotransferase in various organs and on the level of tryptophan in the liver and plasma of rats. Physiol Bohemoslov 1977;26:557-563.

38 Peters DA: Maternal stress increases fetal brain and neonatal cerebral cortex 5-hydroxytryptamine synthesis in rats: a possible mechanism by which stress influences brain development. Pharmacol Biochem Behav 1990;35:943-947.

39 Sedlmayr P, Blaschitz A, Stocker R: The role of placental tryptophan catabolism. Front Immunol 2014;5:230.

40 Braidman IP, Rose DP: Inhibition of tryptophan oxygenase in rat liver by steroid hormones. Biochem J 1970;118:7P-8P.

41 Badawy AA: Effects of pregnancy on tryptophan metabolism and disposition in the rat. Biochem J 1988;255:369-372.

42 Badawy AA: Tryptophan metabolism, disposition and utilization in pregnancy. Biosci Rep 2015;35:e0261.

43 Rennie MY, Mu J, Rahman A, Qu D, Whiteley KJ, Sled JG, Adamson SL: The Ultraplacental, Fetoplacental, and Yolk Sac Circulation in the Mouse. San Diego, Elsevier, 2014, pp 201210.

44 Myatt L: Placental adaptive responses and fetal programming. J Physiol 2006;572:25-30.

45 Hsiao EY, Patterson PH: Placental regulation of maternal-fetal interactions and brain development. Dev Neurobiol 2012;72:13171326.

46 Bronson SL, Bale TL: Prenatal stress-induced increases in placental inflammation and offspring hyperactivity are male-specific and ameliorated by maternal antiinflammatory treatment. Endocrinology 2014;155:26352646.

47 O’Donnell K, O'Connor TG, Glover V: Prenatal stress and neurodevelopment of the child: focus on the HPA axis and role of the placenta. Dev Neurosci 2009;31:285-292.

48 Moe AJ: Placental amino acid transport. Am J Physiol 1995;268:C1321-C1331.

49 Bonnin A, Goeden N, Chen K, Wilson ML, King J, Shih JC, Blakely RD, Deneris ES, Levitt P: A transient placental source of serotonin for the fetal forebrain. Nature 2011;472:347350 .

50 Ligam P, Manuelpillai U, Wallace EM, Walker D: Localisation of indoleamine 2,3-dioxygenase and kynurenine hydroxylase in the human placenta and decidua: implications for role of the kynurenine pathway in pregnancy. Placenta 2005;26:498-504.

51 Nicholls T, Nitsos I, Smythe G, Walker DW: Kynurenine production and catabolism in fetal sheep with embolized or nonembolized placentas. Am J Obstet Gynecol 2001;185: 988-995.

52 Beggiato S, Sathyasaikumar KV, Notarangelo FM, Giorgini F, Muchowski PJ, Schwarcz R: Prenatal kynurenine treatment in mice: effects on placental and fetal brain kynurenines. Soc Neurosci Abstr 2014;39:51.05.
53 Notarangelo FM, Schwarcz R: Prenatal LPS exposure preferentially increases kynurenine pathway metabolism in the fetal brain. Soc Neurosci Abstr 2015;40:74.02.

54 Sano M, Ferchaud-Roucher V, Kaeffer B, Poupeau G, Castellano B, Darmaun D: Maternal and fetal tryptophan metabolism in gestating rats: effects of intrauterine growth restriction. Amino Acids 2016;48:281-290.

55 Notarangelo FM, Goeden N, Pocivavsek A, Beggiato S, Wons K, Bonnin A, Schwarcz R: Kynurenic acid in the fetal mouse brain: on the role of mother-placenta-fetus dynamics. Soc Neurosci Abstr 2016;41:845.29.

56 Ceresoli-Borroni G, Schwarcz R: Perinatal kynurenine pathway metabolism in the normal and asphyctic rat brain. Amino Acids 2000;19:311-323.

57 Beggiato S, Notarangelo FM, Schwarcz R: Maternal, placental and fetal KYNA production in mouse tissue slices. Soc Neurosci Abstr 2015;40:48.19.

58 Schlotz W, Phillips DI: Fetal origins of mental health: evidence and mechanisms. Brain Behav Immun 2009;23:905-916.

59 Jansson LC, Akerman KE: The role of glutamate and its receptors in the proliferation, migration, differentiation and survival of neural progenitor cells. J Neural Transm (Vienna) 2014;121:819-836.

60 Lozada AF, Wang X, Gounko NV, Massey KA, Duan J, Liu Z, Berg DK: Glutamatergic synapse formation is promoted by a7containing nicotinic acetylcholine receptors. J Neurosci 2012;32:7651-7661.

61 Ceresoli-Borroni G, Guidetti P, Amori L, Pellicciari R, Schwarcz R: Perinatal kynurenine 3-hydroxylase inhibition in rodents: pathophysiological implications. J Neurosci Res 2007;85:845-854.

62 Alexander KS, Pocivavsek A, Wu HQ, Pershing ML, Schwarcz R, Bruno JP: Early developmental elevations of brain kynurenic acid impair cognitive flexibility in adults: reversal with galantamine. Neuroscience 2013;238: 19-28.

63 Forrest CM, Khalil OS, Pisar M, McNair K, Kornisiuk E, Snitcofsky M, Gonzalez N, Jerusalinsky D, Darlington LG, Stone TW: Changes in synaptic transmission and protein expression in the brains of adult offspring after prenatal inhibition of the kynurenine pathway. Neuroscience 2013;254:241-259.

64 Forrest CM, McNair K, Pisar M, Khalil OS, Darlington LG, Stone TW: Altered hippocampal plasticity by prenatal kynurenine administration, kynurenine-3-monoxygenase (KMO) deletion or galantamine. Neuroscience 2015;310:91-105.

65 Khalil OS, Pisar M, Forrest CM, Vincenten MC, Darlington LG, Stone TW: Prenatal inhibition of the kynurenine pathway leads to structural changes in the hippocampus of adult rat offspring. Eur J Neurosci 2014;39: 1558-1571. 
66 Pershing ML, Bortz DM, Pocivavsek A, Fredericks PJ, Jorgensen CV, Vunck SA, Leuner B, Schwarcz R, Bruno JP: Elevated levels of kynurenic acid during gestation produce neurochemical, morphological, and cognitive deficits in adulthood: implications for schizophrenia. Neuropharmacology 2015;90:33-41.

67 Pocivavsek A, Thomas MA, Elmer GI, Bruno JP, Schwarcz R: Continuous kynurenine administration during the prenatal period, but not during adolescence, causes learning and memory deficits in adult rats. Psychopharmacology (Berlin) 2014;231:2799-2809.

68 Schulz KM, Andrud KM, Burke MB, Pearson JN, Kreisler AD, Stevens KE, Leonard S, Adams CE: The effects of prenatal stress on alpha4 beta 2 and alpha7 hippocampal nicotinic acetylcholine receptor levels in adult offspring. Dev Neurobiol 2013;73:806-814.

69 Baier CJ, Pallares ME, Adrover E, Monteleone MC, Brocco MA, Barrantes FJ, Antonelli MC: Prenatal restraint stress decreases the expression of alpha-7 nicotinic receptor in the brain of adult rat offspring. Stress 2015;18:435-445.
70 Stevens KE, Adams CE, Yonchek J, Hickel C, Danielson J, Kisley MA: Permanent improvement in deficient sensory inhibition in DBA/2 mice with increased perinatal choline. Psychopharmacology (Berlin) 2008; 198:413420.

71 Ricceri L, De Filippis B, Fuso A, Laviola G: Cholinergic hypofunction in MeCP2-308 mice: beneficial neurobehavioural effects of neonatal choline supplementation. Behav Brain Res 2011;221:623-629.

72 Langley EA, Krykbaeva M, Blusztajn JK, Mellott TJ: High maternal choline consumption during pregnancy and nursing alleviates deficits in social interaction and improves anxiety-like behaviors in the BTBR T + Itpr3tf/J mouse model of autism. Behav Brain Res 2015;278:210-220.
73 Fineberg AM, Ellman LM: Inflammatory cytokines and neurological and neurocognitive alterations in the course of schizophrenia. Biol Psychiatry 2013;73:951-966.

74 Zavitsanou K, Lim CK, Purves-Tyson T, Karl T, Kassiou M, Banister SD, Guillemin GJ, Weickert CS: Effect of maternal immune activation on the kynurenine pathway in preadolescent rat offspring and on MK801induced hyperlocomotion in adulthood: amelioration by COX-2 inhibition. Brain Behav Immun 2014;41:173-181.

75 Schröcksnadel K, Widner B, Bergant A, Neurauter $\mathrm{G}$, Schennach $\mathrm{H}$, Schröcksnadel $\mathrm{H}$ Fuchs D: Longitudinal study of tryptophan degradation during and after pregnancy. Life Sci 2003;72:785-793.

76 Notarangelo FM, Wu HQ, Macherone A, Graham DR, Schwarcz R: Gas chromatography/tandem mass spectrometry detection of extracellular kynurenine and related metabolites in normal and lesioned rat brain. Anal Biochem 2012;421:573-581. 